\title{
Discussion on the Importance of Performing Art in Teaching of Broadcasting and Hosting
}

\author{
Qianqian $\mathrm{Wu}$ \\ School of Humanity and Law \\ Nanyang Institute of Technology \\ Nanyang, Henan, China 473004
}

\begin{abstract}
The broadcasting and hosting art and performing art belong to the category of art. They have common characteristics in the fields such as creating environment, creation process and creation means, moreover, the job category of host is also a kind of special social performance. However, at present, the broadcasting and anchor major in many colleges pays no attention to the offering of performance course, which lead to the situation that many students have weak foundation of lines, stiff body movement, single hosting style and lack tension and expressive force on the stage. Therefore, it is essential to introduce performing art into the teaching on broadcasting and hosting as soon as possible and train students' performance abilities from aspects of liberating nature, improving sensibility, releasing emotion and impromptu performance, etc.
\end{abstract}

Keywords-performing art; broadcasting and hosting art; performance training

\section{INTRODUCTION}

Broadcasting and anchor major appears in Beijing Broadcasting Institute in 1950s. For decades, it develops vigorously and flourishes everywhere and has cultivated a large number of outstanding artistic talents for our country, but meanwhile, many problems also appear gradually, such as choose school with low marks in the selection mechanism, teaching system disconnected from society and course design ignores practice, etc. Among many of the problems, according to teaching experience, the author concludes that many colleges lack basic course teaching of performing art on course design. Performance ability occupies a very important position in training objectives of broadcasting and anchor major. It is one of the necessary professional qualities of broadcasters and hosts, and concerns the width and breadth of career development after students go to work. On this issue, many predecessors who research broadcasting and hosting art have conducted many beneficial explorations. On this basis, this article takes the importance of performing art in broadcasting and anchor major as the argument, and takes the common ground between performing art and broadcasting and hosting art as the basis, summarizes the important significance of performance training for creation activities of broadcasting, teases several means to enhance students' performance quality, such as liberate nature, improve sensibility, release emotion and impromptu performance, etc., hoping to have some helps on the teaching work of broadcasting and hosting art.

\section{INTERCOMMUNITY BETWEEN PERFORMING ART AND BROADCASTING AND Hosting ART}

In dictionary, the explanation of "performance" refers to "play a musical instrument, stage a play and recite poetry directly or with the help of technical equipments by using sound, expressions and movements to publicly make the works be reproduced." Broadcasting and hosting art is an artistic form of "second creation". Broadcasters and hosts use language and paralanguage to convey information for audiences in the radio and television through voice tube and camera. It belongs to mass communication.

Because of the use of propagation medium, namely the audio and video capture and broadcast equipment, the creation activities of broadcasters and hosts have the property of "relationship between audience and performers". The so-called "relationship between audience and performers" refers to that the work of broadcasting and hosting is a kind of performance "in front of the public". Human performing study thinks that to judge whether a behavior belongs to the category of "performance", we need to see whether the environment that it appears in has "performer-actor relationship", that is to say, whether the behavior organizer realizes his behavior is in the public environment and be willful to "do for others to see". From this point of view, the transmission tasks undertook by broadcasters and hosts decide their behaviors are "in front of the public". They often have to deliberately modify and improve themselves according to the feedbacks from audiences to reach the best communicating effect. Therefore, the "property of facing the public" of artistic creation of broadcasting and hosting decides it has intercommunity with performing art. It is because that "as long as realizing someone is watching, people tends to consciously or unconsciously try to control their actions and expressions... the goal is to give some anticipated impression on the audiences. We can say he enters the state of performance. Because any people who make an attempt to control his image have contradictions between the role and himself, the external image and inherent essence, which has no difference from professional actors." [1] 


\section{A. Virtuality of Creating Environment}

The creating environment of broadcasting and hosting has the characteristic of "virtuality", especially radio broadcast and TV news broadcast. There aren't real audiences in front of broadcasters and hosts. They only face the voice tube and camera. The feelings of communicating with audiences must conduct through reappearance of scene, imagination and association. It determines that broadcasters and hosts must have strong performance desire and ability and convey information, guide public opinion, education and entertainment in an environment that "no one appreciates". It happens that there is a similar case, drama, film and television actors also play roles in specified scene according to the play. The creating environment also has virtuality. Professor Liang Bolong of Central Drama Academy in Peking points out in his works that, "the specified circumstance is a kind of assumption existed in the creation of performance. It not only includes the assumptions created by playwrights, but also includes the assumptions created by directors, actors, and art workers (set design, motion picture setting, lighting, clothing and facial makeup), and workers responsible for the sound effects, etc. Specified circumstance is not a real objective existence. It is the 'fiction of art' cocreated by playwrights, directors, actors and art workers." Therefore, the creating environments of broadcasting and hosting art and performance art are "fictitious" and "assumed". [2]

\section{B. Initiative of Creation Process}

The text operation mode of broadcasters and hosts has three kinds: full-text operation, half text operation and operation without text. Full-text operation refers to that the creation subject of broadcasting makes second creation totally according to the manuscripts. Half text operation is a kind of operation mode of outline. Operation without text mainly refers to impromptu oral expression. No matter any operation mode, it needs broadcasters and hosts to give play to their subjective initiative, use verbal language and paralanguage to mobilize their thoughts and feelings to make them at the state of motion and carry out proactive broadcast creation. Performance also includes impromptu creation and non impromptu creation. Conventional performance needs actors to finish role play and presentation of lines according to the play, turn written play into sound and image symbols, bring stimulation for audiences in seeing and hearing; impromptu performance needs actors to base on few lines or hints, feel and organize language and actions and shape characters according to their understanding. From the perspective of creation process, broadcasting, hosting and performance are second creation. They need to turn written symbols (may be rich and sufficient, also may be few and simple) on their hands into sound and image symbols on the basis of understanding context (specified circumstance).

\section{Duality of Creation Means}

The means of broadcasting creation activities include verbal language and paralanguage. Broadcasters and hosts connect the content and purpose of communication with audio-visual interest and comprehension and feelings of listeners, audiences and net citizens through the creation of verbal language and paralanguage. Verbal language requires broadcasters and hosts to have normative mandarin, standard broadcasting phonation and fluent language expression, etc. Paralanguage includes expression in eyes, facial expression, postures, costume, makeup and appearance, which are mainly used to convey attitudes and emotions and assist the expression of verbal language. The creation means of performance art also include verbal language and paralanguage, namely lines and body movements. Performing art is an art of "action". Dramatic actors finish role shaping by relying on "action". "Action refers to the combination of psychological action, body action and language action that have vested purpose. They are organized on the stage or in front of the camera." [3]

\section{The SignificANCE OF BRING PERFORMANCE ART IN TEACHING ON BROADCASTING AND HOSTING}

The performance elements in performing art can be divided into "five abilities" and "six senses". "Five abilities" are observation ability, imagination, ability of sense, comprehensive ability, and strain capacity respectively; "six senses" are sense of propriety, sense of humor, sense of belief, sense of rhythm, sense of image and sense of reality. The nature of performance is to make performers concentrate on things that they suppose to do and achieve listening, seeing and feeling truly. It is the truest and most vivid performance only by fully applying elements to it. The "sense" of broadcasting and hosting also need real feelings and rich imagination, keen observation, dedicated attention, tactful reaction, flexible adaptation, solid memory, vivid performance and accurate understanding for operating text. The acquisition of these abilities must go through long-term training and repeated practice. The training mode and practice method should refer to the "five abilities" and "six senses" of performing art.

\section{A. Performance Training Helps to Shape Artistic Image}

As mentioned above, "facing the public" is the nature of broadcasting and hosting work. Its existence determines the work of broadcasters and hosts doesn't mean saying to themselves, neither casual conversation in daily life, but conveying information in the environment of "facing the public". This creation characteristic puts forward some requirements for the state of creation, because "facing the public" means change and adjustment. Therefore, broadcasters and hosts should not only convey information in front of voice tube and camera, but also pay attention to their images. This kind of image includes government image as well as personal image.

On the stage, hosts have to convey information and shape artistic image. Similar to actors, broadcasters and hosts should have role awareness in the program and make it clear that their language, action and expression have close relationship with the nature of program. Because of the difference of program type and content, broadcasters and hosts must adjust their own state every now and then to make hosting style conform to the nature of program and receptive psychology of audiences. No matter the shaping of artistic 
images or the change of hosting style, they are not the revivification of real life, but the presentation of performing art. Therefore, in the teaching on broadcasting and hosting, reasonable performance training can help students to overcome shy and timid psychology, greatly mobilize students' enthusiasm and initiative and make perfect broadcast creation as far as possible in role positioning.

\section{B. Performance Training Helps to Trigger Real Feelings.}

With diversification of program forms, entertainment program and reality show program are inundated with the television screen. More and more hosts need to join in the "game" and "role" of program. It requires hosts to get inspiration at the studio, use real feelings to immerse in the program, use paralanguages such as expression, gestures and body languages and the expression of verbal language to accurately and properly express opinions and emotions, and rapidly and wittily make response in communication and dialogue at the scene and then complete the creation in the studio. The true feeling is the key to decide that the social performance of hosts is excellent and the image in the studio is full.

For example, Li Rui, the host in Dad Where We Go, the parent-child reality show program in Hunan Satellite TV, uses the identity of village head to participate in the process of the program. In each phase of the program, he plays different roles to play games and interact with distinguished guests. In order to make the role of the host more vivid and real, there must have real performance training. The hosts can host as well as perform. Only this can they meet the requirements of "reality show" program for "true" and truly attract audiences. Therefore, the outburst of authenticity and true feelings cannot be trained in a day. It requires hosts to carry through systematic training and practice of performance ability.

\section{ANALYSIS ON THE APPLICATION OF PERFORMING ART IN TEACHING}

\section{A. "Liberation of Nature"}

"Liberation of nature" is a terminology in theatrical performance major created by Stanny Lavschi. "Natural instincts" is "nature", namely restore to the nature of life. Although performing art and broadcasting and hosting art have many things in common in the creation process, the training objective of "liberation of nature" in broadcasting and hosting should be different from theatrical performance major and pay more attention to the harmony of natural state and the state of facing the public.

In teaching practice of broadcasting and hosting, it often appears that students dare not to perform on the stage because of being "shy" or "timid" and lack strain and expressive force on the stage. For example, some students can recite poetry with true feelings and the process is touching under the stage, but once going on the stage, they will be at a loss, the breath weakens and the voice is shivering, let alone proper use of postures and language. Furthermore, some students dare not to turn on the light when record in the studio and like to shape their voice and release true feelings in the dark. Once the projector lamp shines on them, they will totally lose the state. These phenomena are because of severely lacking the training of "liberation of nature".

For students in broadcasting and hosting major, they can begin from simply making faces and imitating animals when "liberating nature". On this basis, they can do the training of "five abilities" (observation ability, imagination, ability of sense, comprehensive ability, and strain capacity). For example, by "looking into the mirror" or "observing the action of desk mate", train observation ability; by "reappearance of scene", train imagination and ability of sense; by "mini- games", train strain capacity, etc. All in all, "liberation of nature" is the basis of performance training. The performance teaching in broadcasting and hosting major should base on specialty features and have moderate liberation of nature, let students bring the state under the stage onto the stage and put the recording state in the dark under the projector lamp.

\section{B. Enhance Sensibility}

Any college that opens broadcasting and hosting major will place the improvement of expression ability of verbal language on the core position of training objective. Because the job undertook by talents in broadcasting and hosting major has close relationship with language application. The expression ability of verbal language directly concerns the quality of work. [4] Sensibility is the basis of verbal language expression. Especially in broadcasting that has manuscript, because the work of broadcasting and hosting belongs to "second creation", most manuscripts broadcasted by broadcasters and hosts are the direct feelings of producer directors or journalists instead of the direct experience of broadcasters and hosts. It requires the creation subjects of broadcasting to have abundant sensibility and can bring reappearance of scene through Chinese characters, and then mobilize their thoughts and feelings and make it in the moving state.

In teaching practice, teachers can train students' sensibility by letting them performing professional drama fragments. Teachers can choose classic dramas known by students, lead students to analyze and feel background and clue of the story, traits of role's characteristics, and characteristics of the dialogue, demand students to make the scene of drama reappear through their verbal language and body language. It requires students to accurately and profoundly feel drama elements in teachers' analysis and perform fluently and naturally in front of audiences.

\section{Impromptu Performance}

The biggest difference in broadcasters, hosts and actors lies in: once the role is determined, the actor must perform according to the play. If it is unsuccessful for one time, he can do it for the second and third time. While the work of broadcasting and hosting is always one-pass. With the appearance of more and more live programs, the creation activities of broadcasting from broadcasters and hosts are completed by one time and there is no opportunity to rework. 
Therefore, it needs teachers to train students' abilities to keep their countenance and adapt themselves to changing circumstances and can broadcast or host off the cuff when facing emergencies.

In the teaching practice of broadcasting, teachers can let students watch successful "stage-vacancy-filling" cases of excellent broadcasters and hosts in recent years: for example, in the program of Happy China Tour in 2007, the "Golden Three Minutes" of Dong Qing; the excellent "stage-vacancyfilling" of Wang Han in March 28, 2015, when it is in the final of I am a Singer that Sun Nan suddenly announces to withdraw, etc., and make students feel the importance of impromptu performance. On this basis, teachers can find some simple plays or objects to let students make impromptu performance. In the process of performance, teachers can properly set up obstacles to train students' ability to deal with emergencies and their psychological enduring capacity when facing accidents.

\section{CONCLUSION}

Performance ability is one of the training objectives of broadcasting and anchor major. In the teaching on broadcasting and hosting, properly adding performance training can help broadcasters and hosts to keep active thinking and clear logic in broadcasting creation activities, and shape more popular artistic images and trigger real and moving thoughts and feelings. It can make the liberation of students' nature and the promotion of basic professional skills complement each other through training modes such as "liberate nature", "enhance sensibility" and "impromptu performance", etc.

\section{REFERENCES}

[1] Sun Huizhu. Social Performance Studies [M]. Beijing: The Commercial Press, 2009.5

[2] Liang Bolong. Theatrical Performance Basis[M]. Beijing: Culture and Art Publishing House, 2002. 183-184

[3] Chen Bing. Join Point of Film Performance and Dramatic Performance[J]. Journal of Beijing Film Academy, 2007.(2):10

[4] Wu Yu, Zeng Zhihua. Research on the Talent Cultivation of Broadcasting and Hosting Major[M]. Beijing: Communication University of China Press, 2009.104 